\title{
PROCESSO DE ENSINO-APRENDIZAGEM DOS CONCEITOS DE ÁCIDOS E BASES COM A INSERÇÃO DA EXPERIMENTAÇÃO UTILIZANDO A TEMÁTICA SABÃO ECOLÓGICO
}

\author{
F. F. DANTAS FILHO ${ }^{1}$, G. N. SILVA ${ }^{2}$, A. S. COSTA ${ }^{3}$ \\ 1,2,3. Universidade Estadual da Paraíba, UEPB, Campus I, Campina Grande, PB \\ dantasquimica@yahoo.com.br \\ Artigo submetido 15/06/2016 - Aceito 04/04/2017 \\ DOI: $10.15628 /$ holos.2017.4714
}

\section{RESUMO}

Atualmente, as práticas experimentais no ensino de Química se tornaram uma ferramenta essencial para o processo de ensino-aprendizagem. Neste caso, analisase que é indispensável à existência de um laboratório nas escolas para a realização de experimentos, o que não impossibilita a prática destes, uma vez que é possível trabalhar com outros espaços, dentre eles, a sala de aula. A Química pode ser trabalhada com materiais alternativos que estão presentes no cotidiano e de baixo custo. Neste contexto, o estudo aborda a temática sabão ecológico, obtido com óleo de frituras nas aulas de Química, seguindo uma proposta didática, implementada numa escola pública de Ensino Médio do Município de Arara- PB, trabalhando os conceitos de funções orgânicas. As atividades desenvolvidas incluíram exposição de conceitos, aplicação de questionários, atividade experimental, além de resolução de questões de vestibulares/ENEM referentes ao assunto. Os resultados evidenciaram que a temática sabão ecológico contribuiu para melhor compreensão de conceitos químicos abordados por parte dos alunos, inclusive, desmistificou com base no conhecimento científico, algumas visões em relação à formação de espuma, à presença de bases na fabricação do sabão e influência do $\mathrm{pH}$ sobre as mãos. Destarte, o tema favoreceu resgatar a cultura de outrora, do aproveitamento de gorduras animais e cinzas de fogão a lenha, para a produção do sabão que era utilizado no uso doméstico pelos nordestinos para lacrar silos de armazenamento de cereais, contribuído assim, para a conscientização ambiental.

Palavras-chave: Sabão ecológico; Proposta didática; Ensino de Química.

\section{TEACHING-LEARNING PROCESS OF THE CONCEPTS OF ACIDS AND BASES WITH AN INSERTION OF THE EXPERIMENTATION USING THE THEME ECOLOGICAL SOAP} \begin{abstract}
Nowadays the experimental practices in chemistry teaching have become an essential tool for teaching and learning process, in this case, it's realized that the presence of a laboratory is essential in schools to conduct experiments, which does not quite make it impossible to the practice of these experiments, since other spaces like the classes can be used to work with. Chemistry can be worked with alternative materials that are present in our daily lives and are low cost. In this context, the study addresses the "ecological soap" theme obtained with frying oil in chemistry class following a didactic proposal implemented in a public high school in the city of Arara state of Paraiba, working with the concepts of organic functions. The developed activities included exhibition concepts, enlargement of questionnaires and experimental activity, as well as resolution of tests questions regarding this theme. The
\end{abstract}

results showed that the "ecological soap" theme contributed to a better understanding of chemical concepts by the students, including demystified some views based on scientific knowledge regarding the foaming, with the presence of bases in the production of soap and its $\mathrm{pH}$ influence on hands. Still, the theme favored rescue the interior of the Northeast culture which used animal fat and the old wood burning stove's ashes to the production of soap that was used in the domestic activities, to seal grain storage recipes and contributed to environmental awareness showing the damage it can cause to the environment.

Keywords: Ecological soap; didactic proposal; Chemistry teaching. 


\section{INTRODUÇÃO}

Nos dias atuais, o ensino de Química deve buscar a aproximação de conteúdos com o cotidiano do aluno, visando contribuir para a construção da cidadania, ajudando o aluno a não pensar somente em si, mas na sociedade o qual está inserido; não apenas na mera transmissão de conhecimentos, onde o mesmo não consegue assimilar determinados conteúdos com o cotidiano e o mundo que o rodeia, ou seja, deve-se ensinar os conteúdos de Química com o intuito de despertar no aluno, a capacidade de participar criticamente nas questões da sociedade. De acordo com Cachapuz, et al. (2005), a relevância do ensino de Química deve-se ao fato de possibilitar à pessoa, o desenvolvimento de uma visão mais crítica sobre a realidade que a rodeia, isso porque, a pessoa pode utilizar seu conhecimento adquirido no cotidiano, analisar diferentes situações e possuir as condições básicas para avaliar assuntos de importância na determinação de sua qualidade de vida. A Química, neste caso, é essencial na educação para a cidadania, uma vez que está inserida dentro da sociedade em determinadas ocasiões. Segundo Santos e Schnetzler (2003), o ensino para a construção da cidadania deve levar em consideração os conhecimentos prévios dos alunos, o que pode ser feito por meio da contextualização dos temas sociais, na qual se solicita a opinião dos alunos a respeito do problema que o tema apresenta, antes mesmo de ser discutido do ponto de vista da química. Além disso, este ensino precisa propiciar condições para que o aluno tenha participação ativa, e consiga construir e reconstruir o conhecimento que venha ajudá-lo na formação de indivíduos capazes de intervir no meio em que vivem. Ainda de acordo com Santos e Schetzler (1996), seria desenvolver "a capacidade de tomar decisões fundamentadas em informações ponderadas às diversas consequências decorrentes de tal posicionamento". Tendo em vista que a Química é uma ciência que está constantemente presente na nossa sociedade, se faz necessário que o cidadão tenha o mínimo de conhecimento químico para poder participar da sociedade tecnológica atual.

Segundo a Lei de Diretrizes e Bases da Educação Nacional (LDB 9.394/96), a principal finalidade da educação é o preparo do educando para o exercício da cidadania. Portanto, "tratase de formar o cidadão-aluno para sobreviver e atuar de forma responsável e comprometida na sociedade científica-tecnológica, na qual a Química aparece como relevante instrumento para investigação, produção de bens e desenvolvimento socioeconômico que interfere diretamente no cotidiano das pessoas" (AGUIAR et al., 2003). Cabe ao professor em sala de aula, a tarefa de fornecer informações químicas fundamentais para que o educando possa prepara-se para participar das decisões da sociedade, construir o conhecimento científico e relacionar os conteúdos com a realidade e o ambiente no qual está inserido. Para tanto, o professor tem que selecionar os conteúdos de modo a relacioná-los, de forma contextualizada e interdisciplinada, com o cotidiano do aluno. Assim, o ensino de Química, voltado à formação do cidadão, deve apresentar aos educandos a visão de ciência como um processo de construção, no qual deve-se levar em conta o caráter histórico da Química, mostrando-a como ciência investigativa, entendendo seus aspectos relativos à filosofia das ciências, enfatizando seu papel social através de experimentações simples e de estudos de aspectos históricos do conhecimento químico.

Desta forma, o presente estudo teve como objetivo principal, investigar as opiniões dos alunos sobre o tema sabão de ecológico, a partir da proposta didática apresentada. 


\section{REVISÃO BIBLIOGRÁFICA}

\subsection{Aspectos históricos sobre a produção de sabão alternativo}

Conforme Reis (2009), uma lenda Romana diz que possivelmente o produto originou-se com a mistura de dois ingredientes: a cinza vegetal que é rica em carbonato de potássio e o sebo animal. O sebo era obtido através da cremação dos corpos como sacrifício feito no Monte Sapo. Quando chovia, o sebo juntamente com as cinzas era carregado para as margens do rio Tibre. As mulheres que ali se encontravam para lavar roupas observaram que aquela mistura ajudava na remoção da sujidade empregando menor esforço físico. O sabão ainda não era utilizado para a limpeza corporal. No final do Império Romano o uso do sabão foi divulgado por recomendação médica como agente de higiene benéfico para a pele. Dentre as ruinas da cidade de Pompéia foi encontrada uma fábrica onde eram produzidas barras de sabão. Após o declínio do Império Romano, o uso já estava bem difundido. No entanto, no decorrer da historia da civilização o uso do sabão declinou, principalmente na Idade Média e no Renascimento, quando o banho não era considerado um hábito popular. Apesar de não ser utilizado para essa finalidade, continuou sendo útil na lavagem de roupas. Somente no século XVIII o sabão voltou a ser utilizado como agente de higiene pessoal. Ao longo dos anos, as receitas de sabão foram se aperfeiçoando, introduzindo novos tipos de óleos, corantes e aromatizantes (REIS, 2009).

Atualmente, os sabões são obtidos a partir de gorduras animais (boi, porco, carneiro, dentre outros) ou de óleos (algodão, soja, vários tipos de palmeiras e outros). Gorduras e óleos são ésteres de ácidos carboxílicos de cadeia longa denominados ácidos graxos. Os lipídios mais simples contendo ácidos graxos são os triacilgliceróis, comumente chamados triglicerídios.

A hidrólise alcalina de glicerídeos é denominada genericamente de reação de saponificação, uma vez que numa reação desse tipo, quando é utilizado um éster proveniente de ácidos graxos, o sal formado recebe o nome de sabão. Para Gomes et al (2005), a reação ocorre com a soda cáustica, sendo um processo muito usado industrialmente e em nível doméstico. Os radicais R1, R2 e R3 representam cadeias carbônicas longas, características de ácidos graxos. Se for utilizada uma base composta por Sódio $(\mathrm{Na})$, o sabão formado será chamado de sabão duro. Se no lugar de sódio tiver Potássio (K), passará a ser chamado de sabão mole. A Figura 1 apresenta a reação de saponificação.

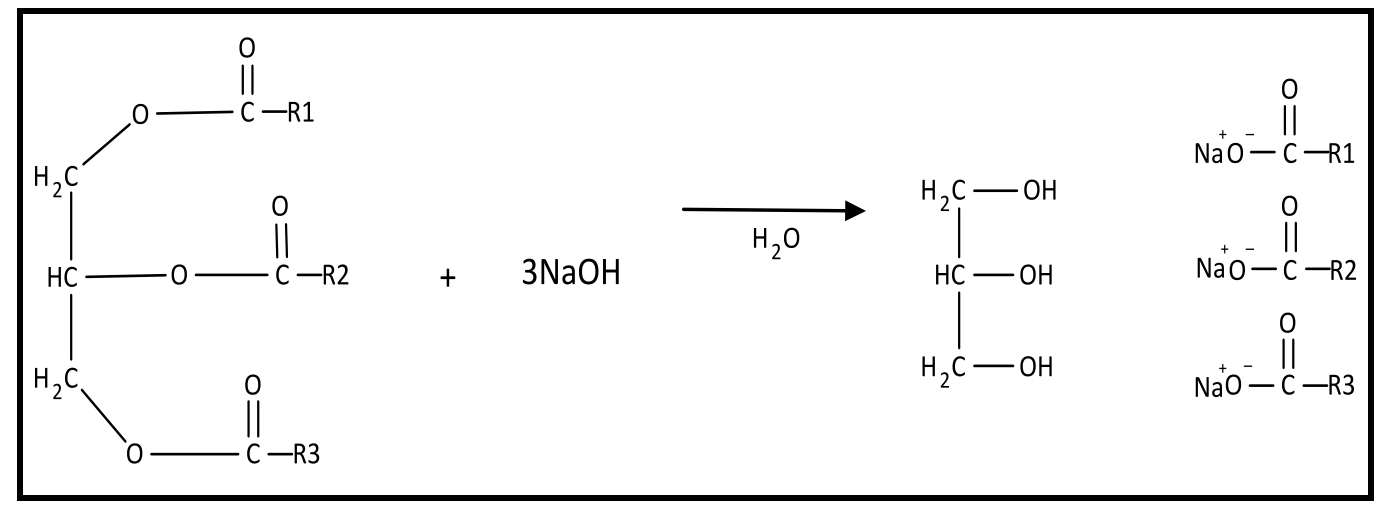

Figura 1: Hidrólise alcalina de óleos ou Gorduras. Fonte: Os autores 
Conforme Campos et al. (2009), a molécula do sabão tem caráter anfótero, propriedade do sabão poder se misturar com o óleo, gordura e água ao mesmo tempo, auxiliando na limpeza as sujidades. A molécula possui uma extremidade carboxílica polar, hidrofílica e outra extremidade hidrocarbônica que é apolar, solúvel em óleos. Esta estrutura permite que os sabões dispersem pequenos glóbulos de óleo em água, possibilitando desse modo, a limpeza e eficiência do sabão.

\subsection{Características gerais dos sabões}

O sabão limpa, porque suas moléculas se ligam tanto às moléculas não polares (gordura ou óleo), quanto polares ( água). Embora a gordura geralmente adira à pele ou à roupa, as moléculas de sabão ligam-se à gordura, tornando-a mais fácil de ser enxaguada em água. Quando aplicada a uma superfície suja, a água com sabão mantém as partículas de sujeira em suspensão para que o conjunto possa ser enxaguado com água limpa.

O hidrocarboneto dissolve sujeira e óleos, enquanto que a porção ionizada torna o sabão solúvel em água. Assim, permite que a água remova matéria normalmente insolúvel em água, por meio da emulsificação. O sabão possui uma longa cadeia carbônica em sua estrutura molecular. Ele é capaz de se solubilizar tanto em meios polares, quanto em meios apolares. Também é tensoativo, ou seja, reduz a tensão superficial da água, proporcionando melhor aderência às superfícies, este processo está representado na Figura 2.

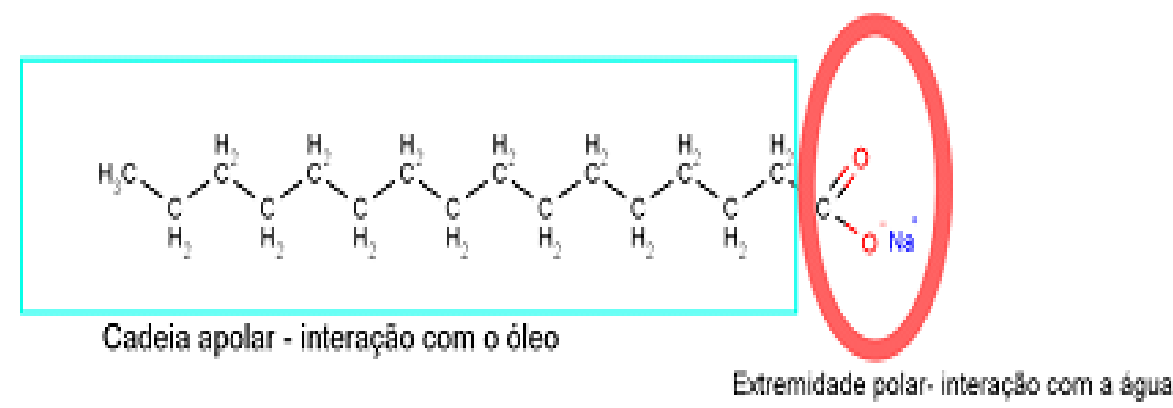

Figura 2: Representação da estrutura molecular do sabão e sua Interação. Fonte: Os autores

\subsection{A importância de reciclar óleo residual para o meio ambiente}

De acordo com a Sabesp (2008), cada litro de óleo despejado no esgoto tem capacidade para poluir cerca de um milhão de litros de água. Essa quantidade corresponde ao consumo de uma pessoa durante 14 anos. Segundo Leal (2011), além dos problemas ambientais, o resíduo de óleo pode causar grandes prejuízos econômicos quando a partir de sua destinação, atinge as tubulações de esgoto. Muitas vezes, as pessoas por falta de conhecimentos e informações não têm noção dos prejuízos causados pelo destino incorreto dado aos resíduos, em especial o óleo de cozinha. Fundamentado nessa carência da sociedade é preciso trabalhar temas ligados à educação ambiental de forma que proporcione à comunidade o conhecimento sobre os impactos e as alternativas viáveis, a fim de resolver esses problemas. E o lugar ideal para promover a educação ambiental é a escola.

A Educação Ambiental deve ser inserida através de projetos que abordem dentre outros temas os resíduos sólidos (JUNIOR, 2009). Embora não exista, um modelo ideal de descarte do óleo de cozinha, uma alternativa para esse é a produção de sabão ecológico. Esse procedimento já vem sendo realizado em diversas cidades do Brasil, através de vários estudos voltados à 
conscientização da sociedade para redução dos impactos gerados pelo óleo, cujos resultados são satisfatórios (LEAL et al., 2011).

A reciclagem do óleo de frituras possui aspectos importantes no processo de ensino e aprendizagem, principalmente, no campo da educação com enfoque na Ciência, Tecnologia, Sociedade e Ambiente (CTSA), vinculada aos aspectos culturais, sanitários, ambientais, econômicos, sociais, políticos e institucionais. A reciclagem é um meio de gerenciamento muito atrativo para o "lixo". Segundo Mano (2005), a reciclagem apresenta diversas vantagens, dentre as quais a preservação do meio ambiente, prática pouca utilizada em nosso país.

\section{METODOLOGIA}

\subsection{Abordagem metodológica}

Tratou-se de um estudo exploratório, com abordagem quali-quantitativa. Conforme Gil (2002, p. 144), "pesquisas exploratórias tem como objetivo proporcionar maior familiaridade com o problema, com vistas a torná-lo mais explícitos ou a construir hipóteses, incluindo levantamento bibliográfico, documental, entrevistas e estudos de caso". Segundo Oliveira (2002), a pesquisa qualitativa descreve a complexidade de uma determinada hipótese ou problema, busca analisar a interação de algumas variáveis, permitindo interpretar particularidades nos comportamentos ou atitudes dos indivíduos.

A metodologia também se baseou em um estudo de caso. Conforme Yin (2001), o estudo de caso é uma estratégia de pesquisa que compreende um método que abrange tudo em abordagens específicas de coletas e análise de dados. É considerada uma análise qualitativa, a qual permite uma investigação para se preservar as características holísticas e significativas dos eventos da vida real, ou seja, um novo modo de relação do ser humano com o mundo, uma nova visão do cosmos, da natureza, da sociedade, do outro e de si mesmo.

\subsection{População e amostra}

Nesta pesquisa, o público alvo foram 62 alunos de uma escola pública do Município de Arara-PB. Os dados foram obtidos na sala de aula. Segundo Bogdan e Biklen (1994), "na investigação qualitativa a fonte direta de dados é o ambiente natural, constituindo o investigador o instrumento principal". Para avaliação da proposta foi aplicado um questionário com questões abertas e na avaliação da aprendizagem os alunos responderam questões de provas do ENEM e de vestibulares vinculadas aos conceitos estudados na proposta de ensino.

Após a aplicação dos instrumentos de coletas de dados os pesquisadores agruparam as respostas para serem analisadas. Para análise dos dados obtidos, utilizou-se o Excel (2010) cujos resultados foram sistematizados na forma de gráficos e discutidos. Para as questões abertas, as falas expressas pelos alunos foram organizadas em quadros e, posteriormente discutidas à luz do referencial teórico.

\subsection{Obtenção do sabão ecológico}

A experimentação é uma atividade que deve ser bem planejada, de modo a ser explorada pelos alunos e professores envolvidos. Este experimento foi realizado com materiais de baixo custo e fácil acesso. Nessas experimentações, procuramos desenvolver uma proposta associando a teoria à prática, pois, sendo a Química de essência experimental, não utilizar esse recurso é 
uma forma de mitigar seu potencial no ensino. Os materiais e roteiros utilizados na produção do sabão ecológico estão listados na Tabela 1.

Tabela 1: Materiais e reagentes utilizados na produção do sabão ecológico

\begin{tabular}{l|l}
\hline \multicolumn{2}{c}{ Materiais e reagentes utilizados } \\
\hline Óleo de cozinha usado & Caixa tipo tetra pak; \\
\hline Água & Luvas; \\
\hline Hidróxido de sódio (NaOH) & Máscara descartável; \\
\hline Suco de limão (coado) & Coador ou peneira; \\
\hline Essência & Balde; \\
\hline Etanol & Colher de plástico. \\
\hline
\end{tabular}

\subsection{Experimentação}

No início do experimento os alunos foram convidados a colocar a máscara e as luvas, devido o hidróxido de sódio ser corrosivo. Por isso, deve ser manuseado com cuidado. Em seguida, adicionaram o hidróxido de sódio na água, sob agitação até completar a diluição; acrescentaram o óleo e mexeram por cerca de 20 a 30 minutos. Na sequência adicionaram o suco do limão e a essência, mexendo por 5 minutos. Na próxima etapa, inseriram álcool etílico e mexeram por mais 10 minutos. Após concluir a saponificação, colocaram o sabão nas caixas tetra pak e deixaram em repouso por 2 dias, cortaram e fizeram as observações.

A utilização de uma abordagem qualitativa-quantitativa no presente trabalho se justifica pelo objetivo principal, que foi: investigar as opiniões dos alunos sobre o tema sabão de ecológico, a partir da proposta didática apresentada. Neste experimento foram abordados os seguintes conteúdos e sua relação com as questões ambientais: Reação de saponificação, ligações químicas e polaridade de moléculas, Cálculos estequiométricos, funções inorgânicas e $\mathrm{pH}$.

\subsection{Descrição da proposta didática para o ensino dos conceitos de funções orgânicas}

O estudo da produção do sabão ecológico foi embasado na elaboração de uma proposta didática, cujo objetivo, foi motivar os alunos a estudar química de forma transversal, no sentindo de contribuir para a compreensão dos conceitos químicos. A proposta foi elaborada para ser executada em 7 aulas de 45 min, abordando o tema: Sabão Ecológico, distribuída em quatro etapas:

1a Etapa (uma aula): Começou com a discussão sobre o sabão e introdução do conteúdo reação de saponificação, a qual foi debatida com os alunos a partir de um conjunto de imagens de óleos de fritura e o descarte inadequado. O objetivo principal foi relacionar o conteúdo de funções orgânicas com a temática do sabão ecológico e fazer com que os alunos comecem a perceber as diferenças entre óleo, gorduras, sabão e detergente.

20 Etapa (duas aulas): Estudo dos ésteres. Este momento teve como finalidade questionar aos alunos as diferenças entre acidez e basicidade no conceito de $\mathrm{pH}$; e trabalhar o conteúdo de estequiometria na prática do sabão ecológico. Os objetivos foram: Fazer com que os alunos conseguissem relacionar as estruturas orgânicas e suas nomenclaturas; relacionar os óleos de 
fritura estudados com a questão ambiental; e despertar a curiosidade sobre os conteúdos trabalhados em sala de aula com a prática do sabão ecológico.

3o Etapa (duas aulas): Este momento foi dedicado à apresentação de breve histórico sobre a produção de sabão de cinza e o industrializado, incluindo os conceitos de funções orgânicas relacionadas às estruturas apresentadas. Desse modo, objetivou-se resgatar a tradição do interior do Nordeste na produção do sabão de cinzas, utilizados para fazer selagem de silos para guardar cereais.

40 Etapa (duas aulas): Aplicação de uma bateria de exercícios pertinente ao tema sabão ecológico, cobrado nos exames do ENEM. A finalidade deste momento foi relacionar a prática desenvolvida com os conteúdos trabalhados em sala de aula; capacitar os alunos para resolução de problemas em exames como o ENEM; e estimular o processo ensino-aprendizagem com o uso de experimentos.

\section{RESULTADOS E DISCUSSÃO}

\subsection{Avaliação da proposta didática pelos alunos do ensino médio da escola pública}

Inicialmente, com a aplicação do questionário buscou-se identificar os aspectos relacionados à: I Avaliação da disciplina de Química pelos alunos da escola; II Atribuições das dificuldades em aprender Química; III Frequência de atividades experimentais desenvolvidas na escola pelo professor; IV Contribuição das atividades desenvolvidas para a aprendizagem dos alunos; V Avaliação do método utilizado pelo professor (monitor) do projeto nas aulas de Química. Em um primeiro momento, buscou-se diagnosticar entre os estudantes a avaliação da proposta pelos alunos da escola, conforme representa o Gráfico 1.

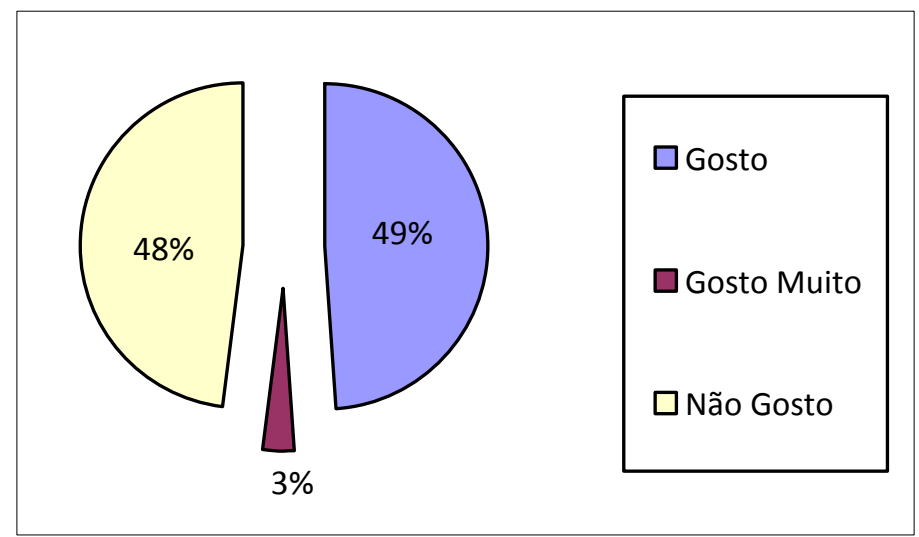

Gráfico 1: Avaliação da proposta de ensino pelos alunos da escola. Fonte: Questionário Aplicado aos participantes

Conforme os dados do Gráfico acima, $52 \%$ dos alunos afirmaram gostar ou gostar muito da proposta usada para o ensino de Química. Em controvérsia, $48 \%$ responderam não gostar. Os que gostam, justificaram ser muito interessante estudar a matéria e os elementos químicos e; outros porque gostam de realizar experiências e ainda, por considerar que a Química auxilia no cotidiano. Os que afirmaram não gostar de Química, relataram que a disciplina é muito difícil e por isso, não se identificam com a matéria por possuir muitos cálculos, o que a torna, segundo os mesmos, muito cansativa.

Desse modo, percebeu-se a necessidade de tornar o ensino de Químico dinâmico e atrativo, que proporcione motivação e prazer em estudá-la, oportunizando que estes alunos 
tenham outra visão sobre a mesma. Para tanto, se faz necessário que o docente busque através de aulas experimentais, atrair a atenção dos mesmos, no sentido de viabilizar uma aprendizagem significativa. Quando questionados sobre o ensino de Química e a proposta apresentada, os participantes responderam conforme está descrito no Quadro 1.

\begin{tabular}{|l|l|}
\hline \multicolumn{2}{|c|}{ Questionário Final } \\
\hline \multicolumn{1}{|c|}{ Perguntas } & \multicolumn{1}{c|}{ Respostas dadas por alguns alunos } \\
\hline $\begin{array}{l}\text { 1. Você considera o ensino de } \\
\text { Química importante na sua } \\
\text { trajetória escolar? }\end{array}$ & $\begin{array}{l}\text { Aluno A: "Sim, porque a Química está em tudo o que } \\
\text { fazemos no nosso dia-a-dia". } \\
\text { Aluno B: "Sim, porque é preciso, para conhecermos } \\
\text { mais ao nosso redor, pois em tudo há Química". } \\
\text { Aluno C: "Sim, porque é uma matéria importante na } \\
\text { escola e em algumas profissões". }\end{array}$ \\
$\begin{array}{l}\text { 2. A forma como vem sendo } \\
\text { ministrada a aula de Química, } \\
\text { está relacionada com o seu } \\
\text { cotidiano? }\end{array}$ & $\begin{array}{l}\text { Aluno B: "Sim, às vezes. Como quando estudamos } \\
\text { sobre ácidos e bases". } \\
\text { Aluno C: "Sim, porque utiliza os produtos que temos } \\
\text { em casa". }\end{array}$ \\
\hline
\end{tabular}

Quadro 1: Perguntas e respostas dadas pelos alunos com referência ao ensino de Química e a proposta apresentada

No que concerne a respeito da importância da Química em sua trajetória escolar, a maioria respondeu que "sim", pois a Química encontra-se presente no cotidiano; outros porque vai ajudar nas futuras profissões de cada um, e também para que consigam entrar em uma universidade. Em um segundo questionamento acerca da forma como vem sendo ministradas as aulas de Química; se tem relação com o cotidiano, os alunos assim, responderam: às vezes sim, em alguns assuntos específicos, com exemplos do cotidiano e de produtos que utilizam em casa.

No que se refere às atribuições das dificuldades em aprender Química os alunos se reportaram conforme os dados descritos no Gráfico 2 .

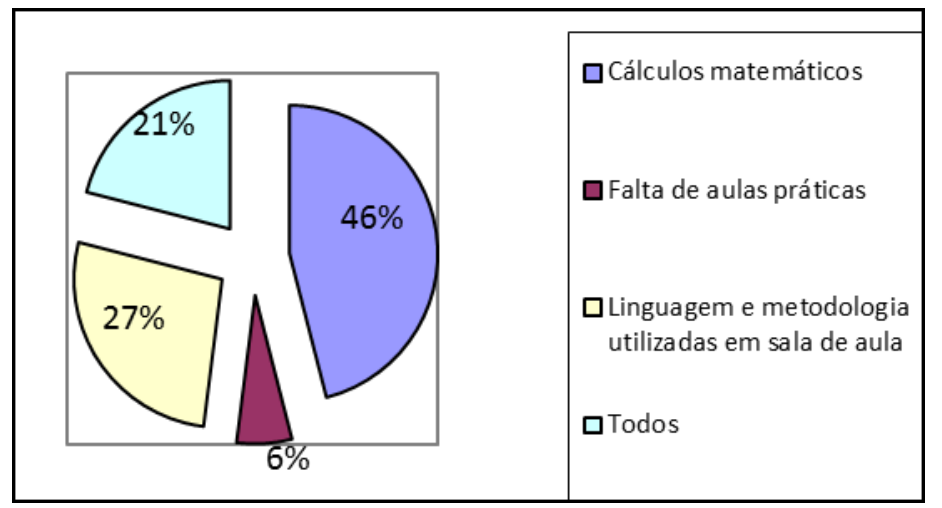

Gráfico 2: Atribuições das dificuldades em aprender Química. Fonte: Questionário Aplicado aos participantes

A principal dificuldade no aprendizado de Química, apresentada pelos alunos de acordo com a avaliação realizada foi atribuída aos cálculos matemáticos, seguido da linguagem e metodologia utilizadas em sala de aula. Logo, os professores devem buscar metodologias de 
ensino que sejm atrativas e que tenham uma finalidade a ser atingida, colaborando para o ensino e para aprendizado dos alunos. Nesse sentido, Castoldi e Polinarski (2009), revelam que há uma influência dos recursos didático-pedagógicos e das atividades criativas na motivação dos alunos na participação e interesse nas aulas. Em seguida, os alunos foram questionados sobre a frequência de atividades desenvolvidas na escola pelo professor. Os resultados obtidos encontram-se no Gráfico 3.

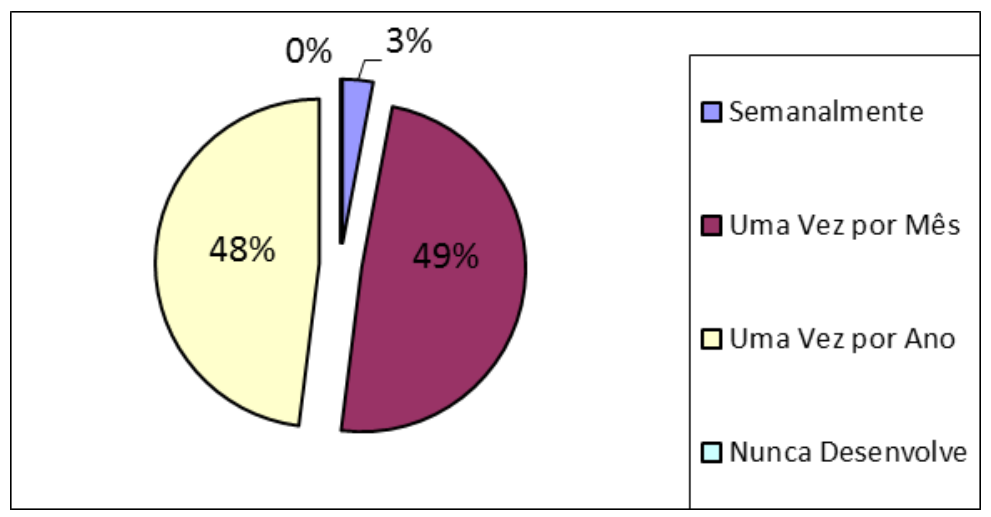

Gráfico 3: Atividades experimentais desenvolvidas pelo professor. Fonte: Questionário Aplicado aos participantes

Exatamente $49 \%$ dos alunos responderam que atividades experimentais são desenvolvidas uma vez por mês na escola; $48 \%$ que as atividades são realizadas uma vez por ano na escola. Uma maneira de contextualizar e trazer a Química para mais próximo dos alunos seria através da experimentação, que permite articular a teoria com prática, levando os alunos a entenderem melhor a Química e aproximar-se do seu cotidiano. Além de ser uma forma de prender a atenção dos alunos e contribuir para a formação do conhecimento, a experimentação tornará as aulas mais dinâmicas e atrativas, assim contribuindo para o processo de ensinoaprendizagem em Química.

Segundo Giordan (1999), a experimentação desperta interesse entre os alunos, independente do nível de escolarização, uma vez que tem caráter motivador, lúdico, vinculado aos sentidos. Logo, em decorrência disso, pode aumentar a capacidade de aprendizado. Deste modo, quanto mais houver integração da teoria com a prática, mais sólida se torna a aprendizagem. Para Wartha e Alário (2005), contextualizar é considerar a vivência e as experiências obtidas, se apropriando também de novos conhecimentos. É elaborar conhecimento no contexto da sociedade em que vive e na estrutura mundial atual. Neste caso, ajuda o aluno a entender a importância de fenômenos e fatores que ocorrem a sua volta.

Em seguida, os alunos foram questionados sobre o que mais tinha lhe chamado atenção na produção do sabão ecológico e a relação dos exercícios aplicados em sala com os conceitos de Química trabalhados na experimentação. No que se refere às atribuições das dificuldades em aprender Química, os alunos se reportaram conforme os dados do Gráfico 4. 


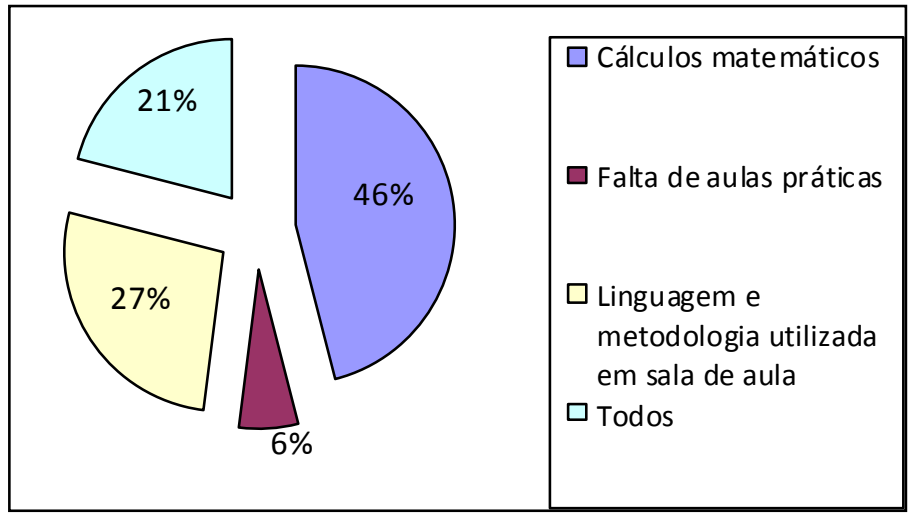

Gráfico 4: Atribuições das dificuldades em aprender Química. Fonte: Questionário Aplicado aos participantes

Percebe-se que a principal dificuldade no aprendizado de Química apresentada pelos alunos foi atribuída aos cálculos matemáticos, seguida da linguagem e metodologia utilizadas em sala de aula. Assim, os professores devem buscar metodologias de ensino que proporcionem melhor aprendizagem dos alunos. Corroborando, Castoldi e Polinarski (2009), revelam que há uma influência dos recursos didático-pedagógicos das atividades criativas na motivação dos alunos na participação e interesse nas aulas.

Logo após, os alunos foram questionados sobre o que mais tinha lhe chamado atenção na produção do sabão ecológico e a relação dos exercícios aplicados em sala com os conceitos de Química trabalhados na experimentação. No Quadro 2 estão expressas as falas dos alunos.

\begin{tabular}{|c|c|}
\hline \multicolumn{2}{|c|}{ Questionário Final } \\
\hline Perguntas & Respostas dadas por alguns alunos \\
\hline $\begin{array}{l}\text { 1. De forma resumida, descreva o que } \\
\text { mais Ihe chamou atenção, em relação } \\
\text { à produção do sabão ecológico? }\end{array}$ & $\begin{array}{l}\text { Aluno A: "Porque pode-se ajudar a cuidar do meio } \\
\text { ambiente através da produção do sabão com óleo de } \\
\text { frituras". } \\
\text { Aluno B: "A utilização do óleo, a reaproveitação e } \\
\text { como podemos fazer algo usando coisas da nossa } \\
\text { casa". } \\
\text { Aluno C: "O fato de produtos simples, que temos em } \\
\text { casa, serem utilizados para fazer sabão". } \\
\text { Aluno D: "A praticidade e o custo benefício" }\end{array}$ \\
\hline $\begin{array}{l}\text { 2. Qual a relação entre os exercícios } \\
\text { aplicados em sala de aula com os } \\
\text { conceitos de Química trabalhados no } \\
\text { experimento da produção do sabão } \\
\text { ecológico? }\end{array}$ & $\begin{array}{l}\text { Aluno A: "A relação entre os dois foi a de ambos } \\
\text { abordarem o conteúdo de ácidos e bases e de reação } \\
\text { de saponificação". } \\
\text { Aluno B: “Com a produção do sabão, conseguimos } \\
\text { resolver os exercícios referentes à reação de } \\
\text { saponificação". } \\
\text { Aluno C: "A relação entre eles, foi a de que o } \\
\text { professor passou a teoria e depois a aula prática". } \\
\text { Aluno D: "Ajudou bastante no nosso entendimento e } \\
\text { para a resolução dos exercícios propostos". }\end{array}$ \\
\hline
\end{tabular}

Quadro 2: Perguntas e respostas dadas pelos alunos com referência ao ensino de Química e a proposta apresentada 
Conforme as respostas descritas no quadro 2 os alunos relataram que a proposta do sabão ecológico chamou a atenção, devido a reutilização do óleo de frituras demonstrar a melhor maneira de cuidar do meio ambiente, de forma prática e baixo custo. Ao relatarem qual a relação entre os exercícios aplicados em sala de aula com os conceitos trabalhados no experimento, observa-se que ambos abordaram conteúdos específicos vistos na aula teórica e depois expostos na aula prática. Com isso, conseguiram resolver a bateria de exercícios proposta. $\mathrm{Na}$ questão seguinte realizou-se a avaliação sobre a contribuição das atividades desenvolvidas para a aprendizagem dos alunos. Os resultados obtidos estão expressos no Gráfico 5.

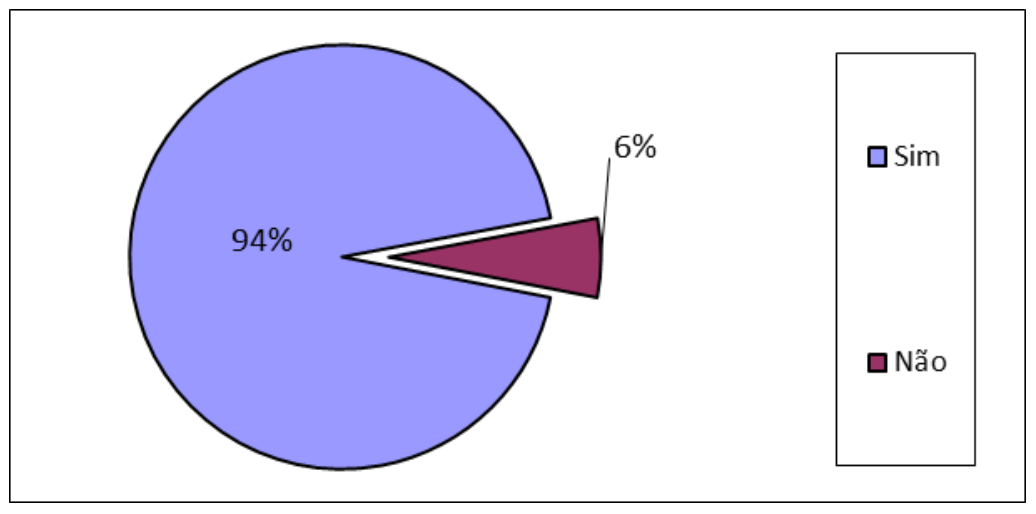

Gráfico 5: Contribuição das atividades desenvolvidas para a aprendizagem dos alunos. Fonte: Questionário Aplicado aos participantes

De acordo com os alunos pesquisados, as atividades desenvolvidas na proposta didática foram satisfatórias e contribuíram na sua aprendizagem. A maioria representada por $94 \%$ dos alunos confirmou a contribuição das atividades desenvolvidas. Os alunos relataram que fica mais fácil de entender os assuntos utilizando este método. Outros, porque perceberam que a junção da teoria com a prática torna o ensino mais proveitoso e obtêm-se um melhor rendimento de aprendizado nas aulas. Em seguida foi avaliado o método utilizado pelo professor (monitor) do projeto nas aulas de Química. Os resultados obtidos estão descritos no Gráfico 6.

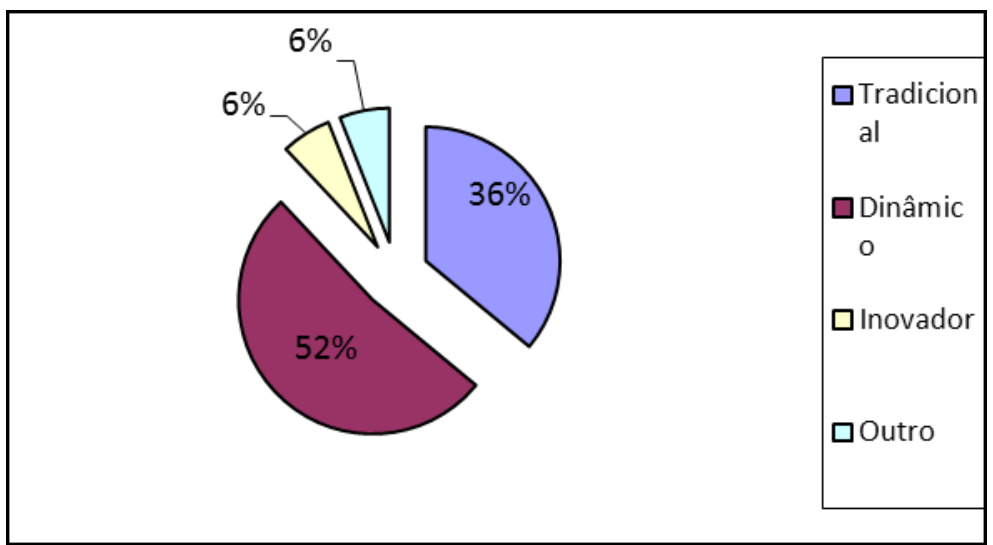

Gráfico 6: Avaliação do método utilizado pelo professor (monitor) nas aulas de Química.

Fonte: Questionário Aplicado aos participantes 
Conforme os dados do Gráfico acima, dos 33 alunos que responderam o questionário final, $36 \%$ avaliaram o método utilizado como tradicional, mais que teve papel importante para a formação de seus conhecimentos. A maioria, representada por $52 \%$ avaliou, o método como dinâmico, pois, tornou a aula mais atrativa e chamou a atenção dos alunos, além de obter elevada participação destes, durante a aula, através de exemplos simples do cotidiano na sala de aula. 6\% dos participantes avaliaram o método como inovador nas aulas de Química; 6\% consideram que o ensino se torna excelente quando se obtêm a junção da teoria com a prática em sala de aula onde os alunos participam de experiências propostas e começam a construir o conhecimento químico partindo da realização de experiências com materiais práticos do cotidiano. Segundo Leach et al (2005), as propostas de ensino apoiadas em temas geradores, surgem como tentativa de aproximar o contexto da pesquisa com a prática em sala de aula.

\section{CONSIDERAÇÕES FINAIS}

Os resultados da pesquisa sinalizam que o ensino de química na escola dos sujeitos participantes não atendendo as perspectivas atuais da educação básica, para tanto se faz necessário que a secretaria de educação deste estado ofereça cursos de formação continuada aos profissionais desta instituição, capacitando - os para novas práticas e metodologias de ensino.

Os resultados da pesquisa mostram que o índice de aceitação da proposta didática é considerado alto e motivador para os pesquisadores, no entanto, é importante destacar que intervenções dessa natureza nos espaços escolares de educação não pode ser algum insolado, deve ser permanentes no processo de ensino e aprendizagem dos alunos.

Os resultados mostraram que os estudantes têm dificuldades em aprender os conceitos de química quando há necessidade de aplicar conhecimentos matemáticos, esta é uma evidencia do modelo de ensino tradicional que se preocupa em transmissão e recepção de conteúdos de forma insolada sem considerar aspectos do cotidiano dos alunos.

É possível considerar que esta proposta de ensino motivou os alunos no estudo desta ciência, conforme os gráficos das Figuras 8 e 9 é possível afirmar que houve interesse dos estudantes nas aulas e durante a execução das atividades foi possível perceber o vislumbre dos estudantes em querer entender os fenômenos problematizados no experimento do sabão ecológico.

É possível considerar que essa proposta de ensino com a inserção de experimentos alternativos corroborou com o processo de ensino e aprendizagem dos conceitos científicos de ácidos e bases, bem como com a conscientização ambiental. Na produção do sabão ecológico reciclaram-se óleos de cozinha, neste experimento mostrou a importância do reuso desse óleo para minimizar os danos que ele pode causar ao ambiente quando descartados de forma inadequada.

Nesse sentido, é relevante pontuar que essas iniciativas vislumbra despertar curiosidade, motivação e interesse nos alunos para estudo da química, bem como atender as prescrições dos documentos referenciais curriculares da educação básica, que prescreve um ensino de forma contextualizada, interdisciplinar e na perspectiva de formar cidadã crítico reflexivo e comprometido com a cidadania. 


\section{REFERÊNCIAS}

Bogdan, R., \& Biklens, S. (1994). Características da investigação qualitativa. Porto: Porto Editora. Cachapuz, A. (Orgs). (2005). A necessária renovação do ensino das ciências. São Paulo: Cortez.

Campos, D. B., Moraes, M. F. P.G., Silveira, R. M. C. F., Resende, L. M. M., \& Mello, R. (2009). Instigando a aprendizagem da Química Orgânica por meio de uma Postura Docente Empreendedora: Processos de Reciclagem de Óleo vegetal e a Obtenção de Sabões em um Estudo Exploratório. I Simpósio Nacional de Ciência e Tecnologia, Paraná, Pr, Brasil.

Castoldi, R., Castoldi, T., \& Polinarski, C.A. (2009). A utilização de recursos didático-pedagógicos na motivação da aprendizagem. I Simpósio Nacional de Ensino de Ciência e Tecnologia. Recuperado de http://www.sabesp.com.br.

Giordan, M. (1999). O Papel da Experimentação no Ensino de Ciências. Química Nova na Escola, 10 (57).

Gomes, A., Sant'Anna, A.P.P., Ramualdo, J., \& Rodrigues, N. (2005). Interação da química com o meio ambiente no cotidiano. Formação Continuada nas Áreas de Ciências da Natureza, Matemática e suas Tecnologias. Rio de Janeiro, RJ, Brasil.

Junior, V.D.M. (2009). Educação ambiental, política, cidadania e consumo. Interações, 11 (3), 214229. Recuperado de http://nonio.eses.pt/interaccoes/artigos/K11\%281\%29. pdf.

Leach, J., Ametller, J., Hind, A., Lewis, J., \& Scott, P. (2005) Desining and evaluating short science teaching sequences: Improving student learning. Research and Quality of Science Education (Eds. Kerst Boersma, Martin Goedhart, Onno de Jong e Harrie Eijelhof) Holanda: Spring.

Leal, C.M. S., Pereira, C. A. L., Ramos, A. P. D., Leite, A. A., \& Oliveira, M. Z. G. C. T. (2011). Educação Ambiental e Gestão de Resíduos: Projeto SOLUZ - Sabão caseiro a partir do óleo de cozinha usado - Ano VI, no quilombo em Alagoa Grande-PB. 3o Fórum Internacional de Resíduos Sólidos. Porto Alegre, RS, Brasil.

Lei no 9.394, de 20 de dezembro de 1996. Dispõe sobre as diretrizes e bases da Educação Nacional. Cartilha da LDB. Ministério da Educação. Brasília-DF, 1997.

Mano, E.B. (2005). Meio ambiente, poluição e reciclagem. São Paulo: Edgard Blücher.

Martins, A. B., Santa Maria, L. C., \& Aguiar, M. R. M. P. (2003). As drogas no ensino de química. Química Nova na Escola, 18 (2), 18.

Reis, M. C. A história do sabão. (2009) Naturlink. [s.n].

Santos, W. L. P., \& Schenetzler, R. P. (1996). O que significa ensino de química para formar o cidadão? Química Nova na Escola - Química e Cidadania, 4 (5), 29.

Santos, W.L.P., \& Schenetzler, R. P. (1996) Função Social: O que significa ensino de química para formar cidadão. Química Nova Escola - Química e Cidadania, 4 (7), 22.

Santos, W.L.P., \& Schenetzler, R. P. (2003) Educação em Química: Compromisso com a cidadania. Ijuí, SP, Editora Unijuí.

Wartha, E. J., Alario, A. F. (2005). A contextualização no Ensino de Química através do Livro Didático. Revista Química Nova na Escola, 22 (6), 35. 